\title{
Hubungan Stadium Hipertensi dengan Derajat Perlemakan Menggunakan Indeks Hepatorenal Sonografi
}

\author{
Dede Marina, ${ }^{1}$ Harry Galuh Nugraha, ${ }^{1}$ Leni Santiana, ${ }^{1}$ Lanny Noor Diyanti ${ }^{2}$ \\ ${ }^{1}$ Departemen Radiologi, Fakultas Kedokteran, Universitas Padjadjaran/RSUP Dr. Hasan Sadikin, Bandung, \\ Indonesia, ${ }^{2}$ Program Studi Magister Ilmu Kedokteran Dasar, Fakultas Kedokteran, \\ Universitas Padjadjaran, Bandung, Indonesia
}

\begin{abstract}
Abstrak
Hipertensi merupakan prekursor perkembangan perlemakan hati nonalkoholik. Modalitas pencitraan USG paling banyak digunakan untuk menegakkan diagnosis perlemakan hati nonalkoholik. Saat ini dikembangkan teknik USG menggunakan parameter indeks hepatorenal sonografi yang dihitung dengan program software ImageJ dan digunakan untuk memprediksi derajat perlemakan hati. Penelitian ini bertujuan mengetahui hubungan antara stadium hipertensi dan derajat perlemakan hati nonalkoholik menggunakan indeks hepatorenal sonografi. Penelitian menggunakan studi observasional analitik dengan rancangan cross sectional, pengambilan sampel dilakukan secara consecutive admission. Penelitian dilaksanakan di Bagian Radiologi RSUP Dr. Hasan Sadikin Bandung periode Juni-Agustus 2016. Subjek penelitian 50 orang, laki-laki 22 orang, perempuan 28 orang, usia termuda 25 tahun, dan tertua 77 tahun. Hasil penelitian melalui uji statistik chi-square menunjukkan derajat perlemakan hati nonalkoholik ringan lebih banyak pada prehipertensi (9 dari 16), derajat sedang pada hipertensi stadium I (10 dari 19), dan derajat berat pada hipertensi stadium II ( 8 dari 15) dengan $\mathrm{p}<0,001$. Perlemakan hati nonalkoholik derajat sedang dan berat lebih sering ditemukan pada perempuan dengan hipertensi $(\mathrm{p}=0,005)$ Simpulan, terdapat hubungan antara stadium hipertensi dan derajat perlemakan hati nonalkoholik menggunakan indeks hepatorenal sonografi.
\end{abstract}

Kata kunci: ImageJ, indeks hepatorenal sonografi, perlemakan hati nonalkoholik, stadium hipertensi, USG

\section{The Association of Hypertension Stage and Non-Alcoholic Fatty Liver Degree Using Hepatorenal Sonography Index}

\begin{abstract}
Hypertension is considered as a precursor to the development of non-alcoholic fatty liver disease (NAFLD). Ultrasonography techniques have been developed using sonography hepatorenal index parameter calculated by ImageJ, that can predict the degree of NAFLD. This study aim to determine the relationship between hypertension stage and the degree of NAFLD using sonography hepatorenal index. The research is an observational using cross sectional methods, with consecutive admission sampling method. The study was performed at Dr. Hasan Sadikin Hospital Bandung from June to August 2016. A total of 50 subjects, 22 men and 28 women, with the youngest 25 and the oldest 77 years old participated. Results indicated that the mild degree of NAFLD were higher on prehypertension (9 of 16), the moderate degree on stage I hypertension (10 of 19), while the severe degree found on stage II hypertension ( 8 of 15), with $\mathrm{p}<0.001$. Moderate and severe degree of NAFLD in hypertensive patient was more common in women $(\mathrm{p}=0.005)$. In conclusion, there is a relationship between hypertension stage and the degree of NAFLD.
\end{abstract}

Key words: Hypertension stage, ImageJ, NAFLD, sonography hepatorenal index, USG

Received: 21 January 2017; Revised: 13 July 2017; Accepted: 20 November 2017; Published: 27 December 2017

Korespondensi: Harry Galuh Nugraha, dr., Sp.Rad.(K.). Departemen Radiologi, Fakultas Kedokteran, Universitas Padjadjaran/ RSUP Dr. Hasan Sadikin, Jln. Pasteur No. 38 Bandung 40161, Jawa Barat, Indonesia. E-mail: hg.nugraha@gmail.com 


\section{Pendahuluan}

Perlemakan hati nonalkoholik atau disebut juga non-alcoholic fatty liver disease (NAFLD) adalah akumulasi lemak dalam jumlah signifikan di dalam sel hepatosit melebihi $5 \%$ berat hati tanpa didahului riwayat mengonsumsi alkohol yang berlebihan sebelumnya, penggunaan obatobatan steatogenik atau kelainan herediter yang menyebabkan perlemakan hati, dan dibuktikan melalui pemeriksaan histologi ataupun modalitas pencitraan. Perlemakan hati yang nonalkoholik mencakup abnormalitas hati dalam spektrum luas meliputi simple steatosis, non-alcoholic steatohepatitis (NASH), fibrosis hati, dan sirosis hati. ${ }^{1-4}$ Data dari American Association for the Study of Liver Diseases (AASLD) pada tahun 2012 menunjukkan bahwa prevalensi perlemakan hati nonalkoholik di dunia mencapai 20\% dari keseluruhan populasi umum. ${ }^{1-3}$ Lazo dkk. ${ }^{5}$ melaporkan prevalensi perlemakan hati nonalkoholik di Amerika Serikat sudah mencapai $21,4 \%$ atau 32,5 juta jiwa berdasar atas data yang diambil dari The Third National Health and Nutrition Examination Survey (NHANES III). Penelitian yang dilakukan Ryoo dkk. ${ }^{6}$ sesuai dengan Michopoulos dkk. ${ }^{2}$ melaporkan bahwa hipertensi berhubungan secara independen dengan perlemakan hati nonalkoholik. Penelitian lain juga melaporkan bahwa stadium hipertensi dapat memengaruhi derajat perlemakan hati nonalkoholik.

World Health Organization melaporkan bahwa prevalensi hipertensi di seluruh dunia meningkat, dari 600 juta kasus pada tahun 1980 menjadi 1 miliar kasus pada tahun 2008.7 Wei dkk. ${ }^{8}$ melaporkan prevalensi hipertensi di negara Eropa mencapai 28-44\%, sedangkan Bell dan Olin ${ }^{9}$ melaporkan penderita hipertensi di Amerika Serikat mencapai 77,9 juta jiwa. Berdasar atas data dari Pusat Data Informasi Kementerian Kesehatan RI tahun 2013 prevalensi hipertensi di Indonesia sebesar 25,8\% atau lebih kurang 65 juta jiwa penduduk Indonesia menderita hipertensi dengan prevalensi tertinggi di Provinsi Kepulauan Bangka Belitung sebesar 30,9\%. Profil Data Kesehatan Indonesia tahun 2011 menyebutkan bahwa hipertensi merupakan salah satu dari 10 penyakit dengan kasus rawat inap terbanyak di rumah sakit pada tahun 2010, dengan proporsi kasus 42,38\% laki-laki dan $57,62 \%$ perempuan..$^{10}$

The Eighth Joint National Committee (JNC 8) tahun 2013 mengklasifikasikan hipertensi menjadi prehipertensi, hipertensi stadium I, dan hipertensi stadium II. Prehipertensi adalah peningkatan tekanan darah dengan tekanan sistole 120-139 $\mathrm{mmHg}$ atau tekanan diastole 8o-89 mmHg. Hipertensi stadium I adalah peningkatan tekanan darah dengan tekanan sistole 140-159 $\mathrm{mmHg}$ atau tekanan diastole 90-99 mmHg, sedangkan hipertensi stadium II adalah peningkatan tekanan darah dengan tekanan sistole $\geq 160 \mathrm{mmHg}$ atau tekanan diastole $\geq 100 \mathrm{mmHg}$. 7,9

Mekanisme yang menghubungkan hipertensi dengan perlemakan hati nonalkoholik belum sepenuhnya dapat dimengerti. Teori "multiple hit" merupakan teori yang paling banyak diterima untuk menjelaskan patogenesis perlemakan hati nonalkoholik dan progresivitasnya dari simple steatosis menjadi non-alcoholic steatohepatitis (NASH). ${ }^{2,11,12}$ Peningkatan aktivitas sistem renin, angiotensin, dan juga aldosteron pada hipertensi yang menginduksi resistensi insulin dianggap memiliki peranan penting dalam perkembangan perlemakan hati nonalkoholik., ${ }^{2,13}$

USG merupakan pemeriksaan tidak invasif, tanpa radiasi dengan ketersediaan yang luas dan biaya terjangkau serta memiliki sensitivitas dan spesifisitas yang cukup tinggi dalam mendiagnosis perlemakan hati nonalkoholik. ${ }^{14,15}$ Teknik USG berdasar atas perhitungan analisis kuantitatif dengan menggunakan cara/program software komputer dalam menilai struktur dan ekogenitas parenkim hepar untuk meminimalisasi penilaian subjektif dari pemeriksa. Parameter yang paling sering digunakan adalah indeks hepatorenal. ${ }^{14,16}$ Borges dkk. ${ }^{17}$ dan juga Webb dkk..$^{18}$ melaporkan hubungan kuat antara indeks hepatorenal dan hasil pemeriksaan histologi biopsi hati penderita perlemakan hati nonalkoholik.

Indeks hepatorenal merupakan perbandingan ekointensitas hati dan korteks ginjal kanan yang dihitung menggunakan program software komputer. ${ }^{14,16}$ Salah satu dari program software yang dapat digunakan untuk menghitung indeks hepatorenal adalah ImageJ yang diperoleh dari The National Institutes of Health. Penelitian yang dilakukan oleh Marshall dkk. ${ }^{19}$ dan Soder dkk. ${ }^{20}$ melaporkan bahwa perhitungan indeks hepatorenal mempergunakan program software ImageJ merupakan metode yang sederhana, terpercaya, dan mudah diakses dengan biaya yang terjangkau untuk mengevaluasi perlemakan hati nonalkoholik. Borges dkk. ${ }^{17}$ dan juga MartinRodriguez dkk. ${ }^{21}$ telah melaporkan bahwa indeks hepatorenal dapat digunakan untuk memprediksi 
derajat perlemakan hati. Martin-Rodriguez dkk. ${ }^{21}$ membagi derajat perlemakan hati menjadi empat berdasar atas indeks hepatorenal, yaitu normal dengan cut point indeks hepatorenal <1,28; perlemakan hati ringan dengan cut point indeks hepatorenal 1,28-1,74; perlemakan hati sedang dengan cut point indeks hepatorenal 1,75-2,28; dan perlemakan hati berat dengan cut point indeks hepatorenal itu $>2,28$. Penilaian derajat perlemakan hati sangat penting untuk dilakukan karena berhubungan erat dengan prognosis dan penilaian respons terapi penyakit perlemakan hati nonalkoholik.

\section{Metode}

Penelitian observasional analitik pendekatan studi potong lintang dilaksanakan di Departemen Radiologi, RSUP Dr. Hasan Sadikin Bandung pada periode Juni 2016 sampai Agustus 2016. Besar sampel ditentukan berdasar atas formula uji hipotesis dua proporsi dan didapatkan bahwa besar sampel yang minimal untuk penelitian ini adalah sebesar 50 orang. Pengambilan sampel dilakukan pada penderita hipertensi di RSUP Dr. Hasan Sadikin Bandung yang masuk ke dalam kriteria inklusi dengan metode non-probability sampling. Cara pengambilan sampel itu adalah melalui consecutive admission, yaitu berdasar atas urutan kedatangan penderita sampai besar sampel minimal terpenuhi. Kriteria inklusi subjek penelitian ini adalah penderita hipertensi dewasa yang berusia $\geq 18$ tahun, saat dilakukan pengukuran tekanan darah ternyata tekanan darahnya termasuk dalam kategori prehipertensi, hipertensi stadium I atau hipertensi stadium II (berdasar atas klasifikasi hipertensi menurut JNC 8). Kriteria eksklusi memiliki riwayat penyakit hepatitis $\mathrm{C}$, memiliki riwayat kelainan herediter yang dapat menyebabkan perlemakan hati nonalkoholik (penyakit Wilson, lipodystrophy, abetalipoproteinemia, Reye's syndrome, LCAT deficiency, dan penyakit Wolman), mengonsumsi obat yang mampu menyebabkan perlemakan hati nonalkoholik (amiodarone, methotrexate, tamoxifen, kortikosteroid, valproate, antivirus), tidak memiliki riwayat gagal ginjal kronik, dan sedang dalam masa kehamilan.

Kriteria pengeluaran penelitian (drop out), yaitu penderita yang tidak kooperatif sehingga pada pemeriksaan USG di daerah transhepatik tidak didapatkan gambaran hati dan ginjal kanan yang jelas atau tidak dapat dilakukan pemeriksaan tekanan darah sesuai dengan tata cara pemeriksaan darah yang telah ditentukan, saat pemeriksaan USG ditemukan kelainan lain seperti tumor atau metastasis pada hati atau ginjal kanan serta asites dan dicurigai terdapat kelainan lain seperti koartasio aorta dan obstruksi arteri di daerah lengan atas.

Persetujuan etik penelitian (etichal clearance) didapat dari Komite Etik Penelitian Kesehatan RSUP Dr. Hasan Sadikin Bandung dengan surat Nomor LB.04.01/A05/EC/251/VII/2016.

\section{Hasil}

Karakteristik subjek penelitian berdasar atas jenis kelamin dan usia penderita hipertensi di RSUP Dr. Hasan Sadikin Bandung dapat dilihat pada Tabel 1. Tabel 1 menunjukkan bahwa pada penelitian ini sebagian besar penderita hipertensi di RSUP Dr. Hasan Sadikin Bandung adalah perempuan, yaitu sebanyak 28 penderita (56\%), sedangkan laki-laki sebanyak 22 penderita (44\%).

Usia rata-rata penderita hipertensi di RSUP Dr. Hasan Sadikin Bandung adalah 53,82 tahun, simpangan baku 11,5 tahun, dan median 54,5 tahun. Rentang usia terbanyak adalah kelompok usia 51-6o tahun sebanyak 17 penderita (34\%) dengan usia paling muda 25 tahun dan usia paling tua 77 tahun (Tabel 1).

\section{Tabel 1 Karakteristik Subjek Penelitian berdasar atas Usia dan Jenis Kelamin pada Penderita Hipertensi}

\begin{tabular}{|c|c|c|c|}
\hline \multicolumn{2}{|c|}{ Usia dan Jenis Kelamin } & \multirow[t]{2}{*}{$n=50$} & \multirow[t]{2}{*}{$\%$} \\
\hline Usia & & & \\
\hline Rata-rata (SD) & $53,8(11,5)$ & & \\
\hline Median & 54,5 & & \\
\hline Minimum & 25 & & \\
\hline Maksimum & 77 & & \\
\hline 18-30 tahun & & 2 & 4,0 \\
\hline 31-40 tahun & & 4 & 8,0 \\
\hline 41-50 tahun & & 12 & 24,0 \\
\hline 51-6o tahun & & 17 & 34,0 \\
\hline$>60$ tahun & & 15 & 30,0 \\
\hline \multicolumn{4}{|l|}{ Jenis kelamin } \\
\hline Laki-laki & & 22 & 44,0 \\
\hline Perempuan & & 28 & 56,0 \\
\hline Total & & 50 & 100,0 \\
\hline
\end{tabular}




\begin{tabular}{lcc} 
Tabel 2 & $\begin{array}{l}\text { Karakteristik Subjek Penelitian } \\
\text { berdasar atas Stadium Hipertensi } \\
\text { pada Penderita Hipertensi }\end{array}$ \\
\hline Stadium Hipertensi & $\mathbf{n}=\mathbf{5 0}$ & $\mathbf{\%}$ \\
\hline Prehipertensi & 16 & 32,0 \\
Hipertensi stadium I & 19 & 38,0 \\
Hipertensi stadium II & 15 & 30,0 \\
Total & 50 & 100,0 \\
\hline
\end{tabular}

Karakteristik subjek penelitian berdasar atas stadium hipertensi pada penderita hipertensi di RSUP Dr. Hasan Sadikin Bandung dapat dilihat pada Tabel 2. Tabel 2 ini menunjukkan bahwa pada pemeriksaan tekanan darah 50 penderita hipertensi di RSUP Dr. Hasan Sadikin Bandung hampir merata, sebagian besar adalah penderita hipertensi stadium I sebanyak 19 penderita (38\%).

Karakteristik subjek penelitian ini berdasar atas derajat perlemakan hati yang nonalkoholik menggunakan indeks hepatorenal sonografi pada penderita hipertensi di RSUP Dr. Hasan Sadikin Bandung dapat dilihat pada Tabel 3. Pemeriksaan USG hati dan perhitungan indeks hepatorenal sonografi ditemukan derajat perlemakan hati nonalkoholik ringan, sedang, dan berat sebanyak $26 \%, 34 \%, 24 \%$.

Hasil analisis uji chi-square pada derajat kepercayaan 95\% terdapat hubungan bermakna antara jenis kelamin dan derajat perlemakan hati nonalkoholik menggunakan indeks hepatorenal sonografi pada penderita hipertensi di RSUP Dr. Hasan Sadikin Bandung ( $p=0,005$; Tabel 4).

Perlemakan hati nonalkoholik derajat normal

\section{Tabel 3 Karakteristik Subjek Penelitian berdasar atas Derajat Perlemakan Hati Nonalkoholik Menggunakan Indeks Hepatorenal Sonografi pada Penderita Hipertensi}

\begin{tabular}{lcr}
\hline $\begin{array}{l}\text { Derajat Perlemakan } \\
\text { Hati Nonalkoholik }\end{array}$ & $\mathbf{n = 5 0}$ & $\mathbf{\%}$ \\
\hline Normal & 8 & 16,0 \\
Ringan & 13 & 26,0 \\
Sedang & 17 & 34,0 \\
Berat & 12 & 24,0 \\
Total & 50 & 100,0 \\
\hline
\end{tabular}

menggunakan indeks hepatorenal sonografi pada penderita hipertensi di RSUP Dr. Hasan Sadikin Bandung lebih banyak pada usia 51-60 tahun (5 dari 8). Perlemakan hati nonalkoholik derajat ringan terbanyak pada usia >60 (7 dari 13), derajat sedang terbanyak pada usia 41-6o (12 dari 17), sedangkan derajat berat hampir merata. Hasil analisis uji chi-square tidak terdapat hubungan yang bermakna antara usia dan derajat perlemakan hati nonalkoholik memakai indeks hepatorenal sonografi pada penderita hipertensi di RSUP Dr. Hasan Sadikin Bandung ( $\mathrm{p}=0,331$; Tabel 5).

Perlemakan hati nonalkoholik derajat normal menggunakan indeks hepatorenal sonografi lebih banyak pada prehipertensi (5 dari 8), derajat ringan lebih banyak pada prehipertensi (9 dari 13), derajat sedang lebih banyak pada hipertensi stadium I (10 dari 17), dan derajat berat lebih banyak pada hipertensi stadium II (8 dari 12). Hasil analisis uji chi-square terdapat hubungan bermakna antara stadium hipertensi dan derajat perlemakan hati nonalkoholik menggunakan indeks hepatorenal sonografi ( $\mathrm{p}<0,001$; Tabel 6).

\section{Pembahasan}

Karakteristik subjek penelitian ini menunjukkan bahwa jenis kelamin perempuan lebih banyak menderita hipertensi daripada laki-laki, yaitu sebanyak 28 orang (56\%). Hal ini sesuai dengan data yang diambil dari Pusat Data dan Informasi Kementerian Kesehatan Republik Indonesia yang menyatakan bahwa prevalensi hipertensi berdasar atas jenis kelamin pada tahun 2013 lebih tinggi pada perempuan dibanding dengan laki-laki, yaitu sebesar $28,8 \%$ dan 22,8\%..$^{22-24}$

Kelompok usia yang paling banyak menderita hipertensi adalah kelompok usia 51-6o tahun dan lebih dari 60 tahun, yaitu 34\% dan 30\% masingmasing dengan usia rata-rata 53,8 tahun. Hal ini sesuai dengan data Riset Kesehatan Dasar yang melaporkan prevalensi hipertensi meningkat seiring dengan pertambahan usia. ${ }^{22,23}$

Terdapat hubungan yang bermakna antara stadium hipertensi dan derajat perlemakan hati nonalkoholik menggunakan indeks hepatorenal sonografi. Penelitian yang dilaksanakan oleh Michopoulos dkk. ${ }^{2}$ melaporkan bahwa hipertensi dianggap sebagai prekursor untuk perkembangan perlemakan hati nonalkoholik.

Mekanisme yang menghubungkan hipertensi dengan perlemakan hati nonalkoholik belum sepenuhnya dapat dimengerti, tetapi data-data 
Tabel 4 Hubungan Jenis Kelamin dengan Derajat Perlemakan Hati Nonalkoholik Menggunakan Indeks Hepatorenal Sonografi pada Penderita Hipertensi

\begin{tabular}{|c|c|c|c|c|c|c|}
\hline \multirow{3}{*}{ Jenis Kelamin } & \multicolumn{5}{|c|}{ Derajat Perlemakan Hati Nonalkoholik } & \multirow{3}{*}{$\mathbf{p}^{*}$} \\
\hline & Normal & Ringan & Sedang & Berat & Total & \\
\hline & $\mathbf{n}$ & n & $\mathbf{n}$ & $\mathbf{n}$ & $\mathbf{n}$ & \\
\hline Laki-laki & 3 & 11 & 4 & 4 & 22 & \multirow{2}{*}{0,005} \\
\hline Perempuan & 5 & 2 & 13 & 8 & 28 & \\
\hline
\end{tabular}

Tabel 5 Hubungan Antara Usia dan Derajat Perlemakan Hati Nonalkoholik Menggunakan Indeks Hepatorenal Sonografi pada Penderita Hipertensi

\begin{tabular}{|c|c|c|c|c|c|c|}
\hline \multirow{3}{*}{$\begin{array}{l}\text { Usia } \\
\text { (Tahun) }\end{array}$} & \multicolumn{5}{|c|}{ Derajat Perlemakan Hati Nonalkoholik } & \multirow{3}{*}{$\mathbf{p}^{*}$} \\
\hline & Normal & Ringan & Sedang & Berat & Total & \\
\hline & $\mathbf{n}$ & $\mathbf{n}$ & $\mathbf{n}$ & $\mathbf{n}$ & $\mathbf{n}$ & \\
\hline $18-30$ & o & 1 & 1 & o & 2 & \\
\hline $31-40$ & $\mathrm{o}$ & 1 & 1 & 2 & 4 & \\
\hline $41-50$ & 2 & 1 & 6 & 3 & 12 & 0,331 \\
\hline $51-60$ & 5 & 3 & 6 & 3 & 17 & \\
\hline$>60$ & 1 & 7 & 3 & 4 & 15 & \\
\hline
\end{tabular}

*Uji chi-square

menunjukkan gangguan regulasi sistem renin, angiotensin, dan aldosteron dianggap memegang peranan yang penting dalam perkembangan perlemakan hati yang nonalkoholik. Peningkatan aktivitas sistem renin, angiotensin dan aldosteron pada hipertensi menginduksi resistensi insulin. Insulin bekerja menekan proses lipolisis pada jaringan adiposa. Resistensi insulin pada jaringan adiposa akan menyebabkan proses lipolisis yang berlangsung terus menerus dan meningkatkan asam lemak bebas plasma. Peningkatan asam lemak bebas plasma menyebabkan akumulasi trigliserida di dalam sitoplasma hepatosit lebih dari $5 \%$ yang menyebabkan perlemakan hati nonalkoholik. ${ }^{2,11,12}$

Penelitian ini juga menunjukkan bahwa perlemakan hatiyang nonalkoholik derajat sedang dan berat mempergunakan indeks hepatorenal sonografi pada penderita hipertensi lebih sering ditemukan pada perempuan dibanding dengan laki-laki. Penelitian sebelumnya menunjukkan hasil yang cukup beragam mengenai hubungan antara jenis kelamin dan perlemakan hati yang nonalkoholik. Penelitian yang dilaksanakan oleh Wang dkk. ${ }^{25}$ melaporkan bahwa perlemakan hati nonalkoholik lebih sering ditemukan pada

Tabel 6 Hubungan Antara Stadium Hipertensi dan Derajat Perlemakan Hati Nonalkoholik Menggunakan Indeks Hepatorenal Sonografi

\begin{tabular}{lccccccc}
\hline \multirow{2}{*}{$\begin{array}{l}\text { Stadium } \\
\text { Hipertensi }\end{array}$} & \multicolumn{6}{c}{ Derajat Perlemakan Hati Nonalkoholik } & \multirow{2}{*}{$\mathbf{p}^{*}$} \\
\cline { 2 - 7 } & Normal & Ringan & Sedang & Berat & Total & \\
\cline { 2 - 6 } & $\mathbf{n}$ & $\mathbf{n}$ & $\mathbf{n}$ & $\mathbf{n}$ & $\mathbf{n}$ & \\
\hline Prehipertensi & 5 & 9 & 2 & 0 & 16 & \\
Stadium I & 2 & 3 & 10 & 4 & 19 & $<0,001$ \\
Stadium II & 1 & 1 & 5 & 8 & 15 & \\
\hline${ }^{*}$ Uji chi-square & & & & & & &
\end{tabular}


perempuan. Penelitian yang dilakukan oleh Pan dkk. ${ }^{26}$ melaporkan bahwa prevalensi perlemakan hati nonalkoholik lebih tinggi pada laki-laki dewasa.

Hasil penelitian ini terbukti tidak terdapat hubungan yang bermakna antara usia dan derajat perlemakan hatiyang nonalkoholik menggunakan indeks hepatorenal sonografi pada penderita hipertensi. Keadaan ini sesuai dengan penelitian yang dilakukan oleh Michopoulos dkk. ${ }^{2}$ yang melaporkan tidak terdapat hubungan bermakna antara perlemakan hati nonalkoholik dan usia pada penderita hipertensi. Hal ini mungkin disebabkan oleh perlemakan hati nonalkoholik dapat terjadi pada seluruh kelompok usia. ${ }^{27}$

\section{Simpulan}

Sebagai simpulan penelitian ini, terdapat hubungan antara stadium hipertensi dan derajat perlemakan hati nonalkoholik menggunakan indeks hepatorenal sonografi.

\section{Daftar Pustaka}

1. Bellentani S, Scaglioni F, Marino M, Bedogni G. Epidemiology of non-alcoholic fatty liver disease. Dig Dis. 2010;28(1):155-61.

2. Michopoulos S, Chouzouri VI, Manios ED, Grapsa E, Antoniou Z, Papadimitriou CA, dkk. Untreated newly diagnosed essential hypertension is associated with nonalcoholic fatty liver disease in a population of a hypertensive center. Clin Exp Gastroenterol. 2016;9:1-9.

3. Chalasani N, Younossi Z, Lavine JE, Diehl AM, Brunt EM, Cusi K, dkk. The diagnosis and management of non-alcoholic fatty liver disease: practice guideline by the American association for the study of liver diseases, American college of gastroenterology, and the American gastroenterological association. Am J Gastroenterol. 2012;107(6):811-26.

4. van Werven JR, Marsman HA, Nederveen AJ, Smits NJ, ten Kate FJ, van Gulik TM, dkk. Assessment of hepatic steatosis in patients undergoing liver resection: comparison of US, CT, T1-weighted dual-echo MR imaging, and point-resolved $1 \mathrm{H}$ MR spectroscopy. Radiology. 2010;256(1):159-68.

5. Lazo M, Hernaez R, Eberhardt MS, Bonekamp S, Kamel I, Guallar E, dkk. Prevalence of nonalcoholic fatty liver disease in the United
States: the Third National Health and Nutrition Examination Survey, 1988-1994. Am J Epidemiol. 2013;178(1):38-45.

6. Ryoo JH, Suh YJ, Shin HC, Cho YK, Choi JM, Park SK. Clinical association between non-alcoholic fatty liver disease and the development of hypertension. J Gastroenterol Hepatol. 2014;29(11):1926-31.

7. Kjeldsen S, Feldman RD, Lisheng L, Mourad JJ,ChiangCE,ZhangW,dkk.Updatednational and international hypertension guidelines: a review of current recommendations. Drugs. 2014;74(17):2033-51.

8. Wei Q, Sun J, Huang J, Zhou HY, Ding YM, Tao YC, dkk. Prevalence of hypertension and associated risk factors in Dehui city of Jilin province in China. J Hum Hypertens. 2015;29(1):64-8.

9. Bell K, Twiggs J, Olin BR. Hypertension: the silent killer: updated JNC-8 guideline recommendations. June 2015 [diunduh 26 Mei 2016]. Tersedia dari: https://c. ymcdn.com/sites/www.aparx.org/resource/ resmgr/CEs/CE_Test_Hypertension_The_ Sil.pdf.

10. Kementerian Kesehatan Republik Indonesia. Profil kesehatan Indonesia 2011. Jakarta: Kemenkes RI; 2012.

11. Ahmed M. Non-alcoholic fatty liver disease in 2015. World J Hepatol. 2015;7(11):1450-9.

12. Brookes MJ, Cooper BT. Hypertension and fatty liver: guilty by association? J Hum Hypertens. 2007;21(4):264-70.

13. Manrique C, Lastra G, Gardner M, Sowers JR. The renin angiotensin aldosterone system in hypertension: roles of insulin resistance and oxidative stress. Med Clin North Am. 2009;93(3):569-82.

14. Lee SS, Park SH. Radiologic evaluation of nonalcoholic fatty liver disease. World $\mathrm{J}$ Gastroenterol. 2014;20(23):7392-402.

15. Singh D, Das CJ, Baruah MP. Imaging of non alcoholic fatty liver disease: a road less travelled. Indian $\mathrm{J}$ Endocrinol Metab. 2013;17(6):990-5.

16. von Volkmann HL, Havre RF, Løberg EM, Haaland T, Immervoll $\mathrm{H}$, Haukeland JW, dkk. Quantitative measurement of ultrasound attenuation and hepato-renal index in nonalcoholic fatty liver disease. Med Ultrason. 2013;15(1):16-22.

17. Borges VF, Diniz AL, Cotrim HP, Rocha HL, Andrade NB. Sonographic hepatorenal 
ratio: a noninvasive method to diagnose nonalcoholic steatosis. J Clin Ultrasound. 2013;41(1):18-25.

18. Webb M, Yeshua H, Zelber-Sagi S, Santo E, Brazowski E, Halpern Z, dkk. Diagnostic value of a computerized hepatorenal index for sonographic quantification of liver steatosis. AJR. 2009;192(4):909-14.

19. Marshall RH, Eissa M, Bluth EI, Gulotta PM, Davis NK. Hepatorenal index as an accurate, simple, and effective tool in screening for steatosis. AJR. 2012;199(5):997-1002.

20. Soder RB, Baldisserotto M, Duval da Silva V. Computer-assisted ultrasound analysis of liver echogenicity in obese and normalweight children. AJR. 2009;192(5):W201-5.

21. Martin-Rodriguez JL, Arrebola JP, JimenezMoleon JJ, Olea N, Gonzalez-Calvin JL. Sonographic quantification of a hepato-renal index for the assessment of hepatic steatosis in comparison with $3 \mathrm{~T}$ proton magnetic resonance spectroscopy. Eur J Gastroenterol Hepatol. 2014;26(1):88-94.

22. Pusat Data dan Informasi Kementerian Kesehatan RI. Hipertensi [diunduh $28 \mathrm{Mei}$ 2016]. Tersedia dari: http://www.depkes. go.id/resources/download/pusdatin/ infodatin/infodatin-hipertensi.pdf.

23. Ramdhani R, Respati T, Irasanti SK. Karakteristik dan gaya hidup pasien hipertensi di Rumah Sakit Al-Islam Bandung. GMHC. 2013;1(2):63-8.

24. Achmad C, Martanto E, Aprami TM, Purnomowati A, Soedjana Ningrat RRF, Febrianora M. Indeks massa ventrikel kiri dengan disfungsi diastole pada pasien konsentrik penyakit jantung hipertensi. GMHC. 2017;5(1):70-6.

25. Wang $\mathrm{Z}, \mathrm{Xu} \mathrm{M}, \mathrm{Hu} \mathrm{Z}$, Shrestha UK, Prevalence of nonalkoholik fatty liver disease and its metabolic risk factor in women of different ages and body mass index. Pub Med. 2015;6:667-73.

26. Pan JJ, Fallon MB, Gender and racial differences in nonalkoholik fatty liver disease. World J Hepatol. 2014;6(5):274-83.

27. Pacifico L, Poggiogalle E, Cantisani V, Menichini G, Ricci P, Ferraro F, dkk. Pediatric nonalcoholic fatty liver disease: a clinical and laboratory challenge. World $\mathrm{J}$ Hepatol. 2010;2(7):275-88. 